\title{
Digital Economy and its Importance in the Development of Small and Medium Innovative Enterprises
}

\author{
Tatiana Korsakova ${ }^{1}$ \\ Advanced Doctorate in Pedagogics \\ Associate Professor \\ Department of Management and Innovational Technologies \\ Institute of Management in Economical \\ Ecological and Social Systems \\ Southern Federal University \\ Taganrog, Russia \\ Lyudmila Dubanevich ${ }^{2}$ \\ $\mathrm{PhD}$ in Economics \\ Associate Professor \\ Department of Economics \\ Moscow Economic Institute \\ Moscow, Russia
}

\author{
Oleg Drozdov ${ }^{3}$ \\ $\mathrm{PhD}$ in Economics, Associate Professor \\ Faculty of Economics, Department of Economic Theory \\ St Petersburg University, St Petersburg, Russia \\ Anna Mikhailova ${ }^{4}$ \\ $\mathrm{PhD}$ in Economics, Associate Professor \\ Department of Sociology and Human Resource Management \\ Finance and Economic Institute \\ North-Eastern Federal University, Yakutsk, Russia \\ Ekaterina Kamchatova ${ }^{5}$ \\ Advanced Doctorate in Economics, Associate Professor \\ Department of Innovation Management \\ Institute of Industry Management \\ State University of Management, Moscow, Russia
}

\begin{abstract}
A single universally accepted definition, levels and interconnections of digital economy with other economies is not yet developed. Thus, various definitions of the digital economy have been investigated, as well as various approaches to describing the process of transformation of the digital economy for the correct establishment of these relationships. The article observes the relationship between the state of the digital economy, innovative small and medium enterprises, the development of small and medium businesses in general. The stage of transformation of the digital economy of Russia is determined at the second, intermediate stage of development and the main barriers to moving to the third level are pointed out. The dual role of the digital economy in the development of small and medium innovative enterprises is determined based on the selected model of $R$. Bukht \& R. Heeks, the two directions of influence being the SMEs provision with necessary tools and the digital economy becoming the object of innovative development of SMEs. Finally, the assessment of the state of digital economy in Russia is given and the recommendations for its further implementation are given.
\end{abstract}

Keywords-Business; SMEs; entrepreneurship; Russia; digitalization

\section{INTRODUCTION}

The intensive development of information technology at the end of the 20th, beginning of the 21st century became an extraordinary phenomenon in terms of its scale and degree of influence and attracted great attention of the scientific community [1]. The patterns of implementation and digital products in all major areas of human activity: management, production, science, education, defense, medicine, etc. are carefully studied by Russian and foreign researchers [2]. Such terms as digital economy (hereinafter referred to as DE) and digitalization of the economy are most often used to describe this level and the corresponding transformation process. In the context of studies related to the research of $\mathrm{CE}$, the terms "innovation", "innovative development", and "innovative enterprise" usually appear.

The genesis of the above concepts, an accurate description of their characteristics and components seems to be a prerequisite for the correct description of the innovative capabilities of small and medium-sized businesses (hereinafter SMBs, SMEs) in the context of DE. The article discusses the history of the appearance of these concepts, marks the stages of transformation of their content in this regard.

Researchers in Russia and abroad use various interpretations and approaches in determining DE, innovative development of SMEs. The authors conducted an analysis of the formulations of Walter Oyken, specialists of the McKinsey Global Institute, the Global Development Institute, as well as the definitions of other researchers on the reviews $[3,4]$ in this regard. Then, despite the sufficient accuracy and clarity of the two-level approach of Professor R. M. Meshcheryakov [5], a choice was made in favor of the three-level approach of $\mathrm{R}$. Bukht and R. Heeks with the third component, reflecting a qualitative change in the relationship of the digital economy and society [6]. The decision is dictated by the relevance of the model of R. Bucht and R. Heeks to the context of this work, as well as the possibility of an adequate representation of the process of phased development of DE within the 
framework of a three-level approach. It should be emphasized that the two-level approach of Professor Meshcheryakov precisely describes this process in modern Russia, which is at the stage of transition to the third level of the Bukht-Heeks.

A similar study was conducted in relation to the concepts of "innovative enterprise", innovative SMEs. A clear distinction of concepts allows us to differentiate the capabilities of SMEs and large businesses in a digital economy. The innovation potential is determined by their ability to detect, disclose, adapt and use new knowledge [7]. Innovative business development requires innovative approaches to its management as well [8]. The results of the study indicate the dual nature of the impact of DE conditions on the development of innovative small and medium endeavors, as well as on the development of SMEs in general. The inevitability of both positive and negative impacts on business depending on the direction of entrepreneurial activity was noted in particular.

\section{LITERATURE REVIEW}

The term "digital economy" was introduced by $\mathrm{N}$. Negroponte in 1995 (according to other sources — Tapscott, 1996) to indicate the circulation of content on digital media characteristic of that era (music, films, pictures, games, etc.) [2]. The term "digital economy" continued to denote a relatively narrow segment of the production of digital products, the field of retail, and various services using the Internet, as well as services that ensure the development of the Internet services sector itself until 2005-2010. A similar outdated interpretation is still found in scientific articles, despite its obvious inadequacy due to the transformation of the concept's content. Digital technologies have transformed from a market niche for specialists to general-purpose technologies that affect all sectors of the economy and society over the past twenty years [4]. The changes are so noticeable and so significant that the transformation of the content of DE concept can serve as a good example of the transition from quantity into quality. To describe qualitative changes, the initial, "classical" interpretation of the content of DE is no longer suitable. New approaches are required for this.

The wording given by Professor B. Panshin [2] will be used in this work. Interpretation of $\mathrm{R}$. Meshcheryakov involves two levels [5]:

1) The classic one: the digital economy is presented as part of the economy that arose with the advent of digital technologies in the implementation of electronic goods and services (e-learning, sale of media content, telehealth, etc.);

2) The advanced one: social (economic) production using digital technologies. This is not just about e-goods, it means the whole chain of goods and services produced using digital technologies (logistics, Internet of things, Industry 4.0, a smart factory, fifth-generation communication networks, engineering services, prototyping, etc.).

$\mathrm{DE}$ is a part of the general economy at the first stage, and it is already a way of social production at the second stage. Indeed, today any country where the Internet is used as a firstlevel digital economy in accordance with the signs of the classic and expanded interpretation of DE concept. The level will not change until the transition to Industry 4.0 and when the entire social product is created using digital technology in general. With this classification, the digital economy of Nigeria, Brazil, and Russia is at the first "classical level", which is possible only with very rough and primitive gradations.

An analysis of the two-level approach of $\mathrm{R}$. Meshcheryakov indicates its certain incompleteness, insufficient accuracy of determining the second level (stage). To identify this shortcoming, attention should be paid to the following fact. The second paragraph includes the Internet of things (IoT), Industry 4.0, but they are included along with logistics, engineering services, and prototyping. Meanwhile, it is widely believed that such phenomena as IoT and Industry 4.0 indicate the onset of the fourth industrial revolution today [9], [10], [11]. Since revolutionary changes mean a sharp transition to something qualitatively new, the emergence of IoT, the emergence and development of Industry 4.0 means a qualitative transition to a new level of the digital economy.

This important point was ignored in the classification of $\mathrm{R}$. Meshcheryakov. Such significant phenomena as IoT and Industry 4.0 are presented in it as a simple extension of the scope of the application of digital technologies. This view is incorrect since the Internet of things and the fourth-generation industry are changing the way of production and the economy as a whole even more dramatically than the use of steam and electricity in due time. An enterprise of level 4.0 with digital prototyping, 3D printing, and robotic production is able to control the operation of the product without human intervention, make design changes, plan production, manufacture, and supply already updated products. Moreover, all this in the case of physical products, as for digital products, this is no marvel any more.

Thus, the second stage in the classification of Meshcheryakov is not expansion, but a qualitative revolutionary change in the industry. This could be named a revolutionary change in the whole way of social production if added to this is the transition to 5th generation communication networks, robotic logistics, and digital services. Under such circumstances, dividing DE into two levels: initial and "revolutionary high" seems to be overly primitive method of classification. It becomes logical to conclude that it is necessary to highlight an additional stage in the formation of the concept of the "digital economy".

The authors formulated their own concept and definition of DE: "part of the total production volume, which is wholly or mainly produced on the basis of digital technologies by firms whose business model is based on digital products or services". Three stages are distinguished.

In reality, since the third level is added in the process of transformation, the previous ones do not disappear. Moreover, the volumes of products manufactured on them can increase with a transition to a higher level in absolute terms, although their share in the volume of $\mathrm{DE}$ is declining in relative terms. The nominal value of DE stage (level) is determined by the prevailing level in its composition. A schematic image of the levels is [6]: 
1) Digital (IT/ICT) sector (includes components production, Software and IT consulting, information services, telecommunications).

2) Digital economy (includes digital services, platform economy, sharing economy, Gig economy).

3) Digitalized economy (includes digital trade, industry 4.0, precision agrotechnics, algorithm economy).

It shows that the previous levels do not disappear but are part of the next. Almost $100 \%$ penetration of digital technologies is not only in all types of business but also in all areas of activity as a whole in accordance with the ideology of the model for this stage.

The distinction of the proposed levels is not indisputable but deserves attention. If the production of components is replaced with the production of "electronic goods", then it is completely identical to the first level of R. Meshcheryakov. The content and boundaries of the 2nd and 3rd levels are undeniable, with the exception of the location of electronic commerce. This type of digital business should be considered an attribute of the 2nd level rather than a sign of the 3rd due to its massive distribution already at the border of the 1 st and 2nd levels.

In the research existing scientific works were analysed in order to establish patterns of DE development and identify various aspects of its impact on the innovative development of SMEs. It allowed formulating and confirming the hypothesis of the dual influence of DE factors on business entities, to determine the types of activities that provide additional benefits, or vice versa, additional difficulties.

Transformation of the common using effects of new technologies in the digital level has its effect on each one branch of economics or social activity and characterizes digital economics. One of the indexes that describe the level of economic digitalization is the global connectivity index (GCI) that is presented by "Huawei Technologies Co. Ltd." For this index creating has been analyzed 40 indicators of two groups of parameters: performance parameters and technological parameters to ensure transformation into the DE. And Huawei Technologies presents GCI each year. Has to be noted, there is data about the close directly proportional relationship of the GCI and Gross Domestic Product of the country [12], [13], [14].

The comparison of statistical Data from the Federal State Statistics Service (Rosstat), the Central Bank, specialized state and non-governmental institutions, as well as data from international organizations: the UN, the World Bank, the OECD, the EBRD, etc. was used as an empirical method. And a significant contribution to understanding the role of DE gives the legal base in the Russian Federation.

The system of procedures used provided an opportunity for a fairly clear idea of the dynamics of the role of DE in the innovative development of SMEs in the period 1990-2018 in general and it's most likely value in the mid-term perspective.

\section{Generalization OF THE MAin Statements}

To show the level of DE in RF it is necessary to consistently receive answers to questions by the presence of signs of all three levels. The results of the verification by attributes are presented in Table I.

It can be seen that DE in Russia is in a transitional state. So, all the signs of the 1 st and 2 nd levels are present, and part of the signs of the 3rd level: network business and electronic commerce [15]. GCI also demonstrates the little level of the DE. So, according to this index for 2020 the highest level of the country digitalization belongs to the United States (GCI score - 87), Singapore (GCI score - 81), and Switzerland (GCI score -81 ). RF has gotten only 42 position (GCI score 50) [16]. The RF economy of free earnings is slightly present, in the volume corresponding to the second level, the economy of joint consumption is even less noticeable, but both sectors are developing rapidly. It is important to note that often the term e-commerce is confused with the concept of e-business, which is significantly differentiated [15].

The transition to the third level depends on the development of two areas: Industry 4.0 and agricultural engineering. Not necessary to take specific types of agricultural machinery (plow, seeder), but, on the whole, agricultural culture as a complex of technologies at all levels of agricultural production, e.g. implementations of universal smart machines [17]. The transition to digital technologies in the agricultural sector will be primarily constrained by human resources and the existing material base. At the moment, both do not allow starting the introduction of DE, but there is the possibility of using innovative ICTs. For example, SMEs in agriculture could participate in international trade on the basis of the platform of the Unified Information Internet Space of the Agro-Industrial Complex [18] to increase the role of DE in developing the innovative component of SMEs.

TABLE I. PIECES OF EVIDENCE OF DE IN RUSSIA FOR RANKING BY THE BUKHT AND HEEKS MODE

\begin{tabular}{|l|l|}
\hline Evidence & Presence \\
\hline Production of digital products & + \\
\hline Information services & + \\
\hline Software, IT consulting & + \\
\hline Telecommunications & + \\
\hline Digital services & + \\
\hline Platform economy & \pm \\
\hline Gig economy & \pm \\
\hline Sharing economy & \pm \\
\hline E-business & + \\
\hline E-commerce & + \\
\hline Industry 4.0 & - \\
\hline Precision agriculture & - \\
\hline Algorithmic economy & - \\
\hline
\end{tabular}


In the world and Russian practice, the criteria for classifying a business as "small business" or "medium-sized" business is applied. The concept of "development of innovative SMEs" implies two components in the general case:

- Application of innovations and innovative technologies in the business processes of SMEs;

- SME participation in the innovative development of the economy.

The points are not conflicting. So, it is necessary to establish the role of DE in the application of innovations in SME business processes and consider the relationship between $\mathrm{DE}$ and the participation of SMEs in various innovative processes.

It is introduction of ICT and digital technologies in general (accounting 1C, Internet, CPM, CAD systems, etc.) starting from about the $80 \mathrm{~s}$ of the last century and to the present moment. Both of them are products of the DE.

An analysis of the global experience of innovative development indicates the significant role of SMEs in this process [19]. The following facts testify to this. $80 \%$ of the patents for the most important inventions of the 20th century were obtained by representatives of SMEs in the USA and Western Europe and belong to small firms. In the 21st century, according to the US National Science Foundation, the share of SMEs in the total number of high-tech companies approaches 90\% [20]. The situation in Western Europe looks similar. Here, the distribution by country of the number of subjects of innovative SMEs in the total number of industrial enterprises is: $75 \%$ in Ireland, $66 \%$ in Germany, $49 \%$ in Finland, $46 \%$ in France, $40 \%$ in Italy, $39 \%$ in UK [21].

If we are looking at GCI, the leader in Europe in 2020 is Switzerland with a GCI score of 81 . Other European countries' GCI rate is demonstrated in Table II.

So, Russia (GCI Score - 50) is in the near GCI level with Romania and Belarus (GCI Score 50 and 46, accordingly).

An analysis of Russian and foreign sources allow to highlight the following characteristic features of the participation of SMEs in the innovative development of production:

1) The SME sector is very active abroad in the field of innovative entrepreneurship, actively investing in research and development. The share of this sector in R\&D expenditures is more than $30 \%$ in OECD countries. It fluctuates at the turn of $70 \%$ in Iceland and New Zealand [22]. The main source of R\&D funding is the state in Russia. The total share of SMEs and large businesses in R\&D expenses amounted to only $28 \%$ in 2015. Companies in the SME sector are initiating the bulk of innovation in the US. The following facts are cited in favor of this conclusion. SME receives 13 times more patents, implements twice as many inventions, implementation terms are half as fast as those of large corporations in the USA. The share of SME is $\sim 50 \%$ of all innovations and latest technologies that form the level of scientific and technical progress [23]. The share of innovative enterprises is $23 \%$ of the total number of SMEs in the European Union [22].

2) SMEs effectively ensure the transit of innovations from scientific developments to the applied sphere and reduce the time and cost of commercializing the results of research. SMEs demonstrate their willingness to work in conditions of high risk and uncertain market prospects.

3) The compact and flexible structure of SMEs is able to quickly adapt, and in favorable conditions, to quickly scale up the business.

4) The innovative activity of SMEs is highly effective. $R \& D$ cost-effectiveness in SME is four times higher than in a larger business, according to the US National Science Foundation. There is also evidence showing that innovative SMEs create 2.5 times more innovations per employee, while their implementation is faster and costs are $75 \%$ lower than for larger companies. [20], [21], [24].

TABLE II. GLOBAL CONNECTIVITy INDEX RATE OF THE EUROPEAN COUNTRIES [16]

\begin{tabular}{|c|c|c|c|}
\hline Rank & ID & Country & GCI Score \\
\hline 3 & $\mathrm{CH}$ & Switzerland & 81 \\
\hline 4 & SE & Sweden & 80 \\
\hline 5 & DK & Denmark & 77 \\
\hline 6 & FI & Finland & 76 \\
\hline 7 & NL & Netherlands & 75 \\
\hline 8 & GB & United Kingdom & 75 \\
\hline 10 & $\mathrm{NO}$ & Norway & 73 \\
\hline 14 & $\mathrm{LU}$ & Luxembourg & 70 \\
\hline 15 & $\mathrm{DE}$ & Germany & 70 \\
\hline 16 & FR & France & 70 \\
\hline 18 & IE & Ireland & 69 \\
\hline 19 & $\mathrm{BE}$ & Belgium & 66 \\
\hline 20 & AT & Austria & 66 \\
\hline 23 & ES & Spain & 61 \\
\hline 24 & $\mathrm{EE}$ & Estonia & 61 \\
\hline 25 & $\mathrm{PT}$ & Portugal & 61 \\
\hline 26 & IT & Italy & 60 \\
\hline 27 & $\mathrm{LT}$ & Lithuania & 58 \\
\hline 28 & $\mathrm{CZ}$ & Czech Republic & 57 \\
\hline 29 & SI & Slovenia & 56 \\
\hline 31 & $\mathrm{HU}$ & Hungary & 54 \\
\hline 32 & SK & Slovakia & 54 \\
\hline 35 & GR & Greece & 52 \\
\hline 36 & BG & Bulgaria & 52 \\
\hline 38 & HR & Croatia & 51 \\
\hline 39 & PL & Poland & 51 \\
\hline 41 & RO & Romania & 50 \\
\hline 47 & $\mathrm{BY}$ & Belarus & 46 \\
\hline 51 & $\mathrm{RS}$ & Serbia & 45 \\
\hline 53 & UA & Ukraine & 43 \\
\hline
\end{tabular}


Investors, when making investment decisions, do this in relation to a specific subject of SMEs, and not the entire sector as a whole. There are studies showing that providing the mainstream of innovation, SMEs lose to large companies in such a key indicator as investment efficiency. Choi K.S. and Choi J. S. [25] obtained a result indicating a lower investment efficiency of SME companies compared to other companies.

Investment efficiency (IE) of enterprise is calculated as a function of investment risk, profitability, and investment management costs, taking into account industry characteristics and limitations. The mathematical apparatus of modern economic science allows calculating IE for a number of economic indicators of the enterprise. Choi K.S. and Choi J. S. formulated the hypothesis of lower investment efficiency of companies in the SME sector. As theoretical assumptions, the researchers put forward the following points:

1) SME company is generally knowledgeable about investors, but investors are generally poorly informed about an SME representative.

2) SME business does not have enough specialists in the field of investments. Often small companies simply do not have the opportunity to hire them. Large companies have such specialists. Assuming that these two factors influence firms' investment performance, Choi K.S. and Choi J. S suggested that the SME sector will detect lower IE levels than other firms.

Choi K.S. and Choi J.S collected data for two years (20112013) for companies listed on the Korean Stock Exchange (KSE) and the Korean Securities Dealers Automated Quotations (KOSDAQ) to test their hypothesis. The selection was made according to the following criteria:

1) Only non-financial firms are studied.

2) Only those firms whose fiscal year ends in December are studied, the sample is 3549 companies/year.

3) Data is excluded if there are no indicators necessary for empirical analysis.

4) The maximum values of the variables are reduced by $5 \%$, and the lowest by $5 \%$ is increased to reduce the effect of emissions.

A regression model was built, and the necessary calculations were made to process the results. Those showed that the level of investment efficiency of the SME business is lower in comparison with other firms. This means that companies in this sector have less potential for long-term growth due to lower IE. This conclusion is consistent with the assumptions of the researchers, confirming that the insufficient number of investment funds and the lack of specialists in the field of investment is the reason for the decrease in the investment efficiency of SMEs. Thus, laws are needed to facilitate lending to SMEs. An example of such legislative activity is the US experience.

The previous subsection defines the degree of participation of SMEs in innovation processes at the global and national levels. There are good reasons to compare their scales, evaluating the contribution of each object to the global and national GDP to further examine the relationship between DE and SME participation in innovative development. Let's start with the digital economy. With respect to the reliable determination of its scale, there are significant obstacles [26]. Without ranking by importance, they are formulated as follows:

1) lack of generally accepted definition of $\mathrm{DE}$;

2) lack of reliable statistics on the main DE components and aspects, especially in developing countries;

3) the methodology for measuring scale lags behind the development of DE.

On a global scale, depending on the definition and measurement methods used, the size of the digital economy is estimated to be from 4.5 to $15.5 \%$ of world GDP [22]. Let's move on to the scale of SMEs. So, according to the International Federation of Accountants, the contribution of SMEs is $\approx 55 \%$ [27].

The contribution of DE to the country's GDP according to the report of the RAEC "Runet Economy / Digital Economy of Russia 2018" and also according to rough estimates amounted to $5.1 \%$ in Russia in 2018. The dynamics of the share of DE in the country's GDP is as follows: $1.6 \%$ in 2011, $1.8 \%$ in $2012,2.1 \%$ in $2013,2.2 \%$ in $2014,2.1 \%$ in 2015 , $3.9 \%$ in $2016,4.6 \%$ in $2017,5.1 \%$ in 2018 [28]. The growth of the digitalization level in the economics of RF is demonstrated also by GCI growth in the global rank: RF rises its position from 48 GCI Scope (2018) to 50 (2020). Moreover, if we determine the relationship between GDP and GCI we can see a close connection. However, nethermind of GCI Scope growing the range of the RF in GCI became lower (from 36 in 2018 to 42 in 2020) because of the better increase of other world digital economics [16], [29]. Moreover, if we determine the relationship between GDP and GCI we can see a close connection between these parameters (1).

$$
\text { GDP }(\text { par })=1514 * \mathrm{GCI}-48390 \text {, }
$$

where the determination coefficient is 0.60 , and the correlation coefficient is 0.77 . This, according to the Chaddock ratio, indicates a close relationship between the factors (GDP and GCI) [30].

The share of SMEs in Russia's GDP was $21.9 \%$ in 2017 according to the FSSS. Thus, statistics show that Russia lags behind developed countries for each of the indicators. It follows that the Government of the Russian Federation should take measures to synchronously develop SMEs and DE to increase their contribution to the country's GDP. It is necessary to take into account their mutual influence in order to increase the growth rate for each indicator in this process.

\section{DISCUSSION}

An analysis of the relationship between SMEs and DE in GDP, both globally and nationally, leads to firm conclusions. The above statistics show that in both cases, the share of SMEs in GDP significantly exceeds the share of DE. As applied to Russia, this means that using the potential of SMEs in the development of DE can equally significantly increase the share of the latter in the Russian economy. In the ideal 
case, if the entire small and medium-sized business of Russia is "turned" today towards the DE, then the share of the latter in GDP can be increased to $21.9 \%$, which would lead the Russian Federation to be the undisputed world leader in this indicator. Moving from an abstract concept to reality, Russia needs to additionally create an innovative sector of small business in volumes comparable to the existing, today, SME sector. The attractiveness of such a solution is obvious. If successful, the country rises in terms of the share of SMEs in GDP to the level of developed countries, while the strategic task of growing the digital economy to the level of $\sim 20 \%$ of GDP and moving it to the third level on the Bukht\&Heeks scale is automatically solved.

It becomes possible to describe how DE is related to the innovative activities of SMEs, and ultimately determine the role of DE in the innovative development of SMEs using the definition of a digital economy, the Bukht\&Heeks scheme, data on the degree of participation of SMEs in innovation processes and the ratio of the scales of CEs and SMEs.

The influence of DE on the innovative development of SMEs occurs in two directions:

1) $\mathrm{DE}$ provides SMEs with modern digital tools for $R \& D$. It is impossible to imagine an innovative process without the use of modern CAD, software for mathematical modeling, and digital three-dimensional modeling, software for engineering research and calculations using FEM methods, without digital products for processing results, cloud computing, visualization tools, as well as modern communication tools today. The same direction should also include products that support the business processes of SMEs (1C products, mobile communications, the Internet, CPM programs, text and image editors, etc.).

2) DE acts as an object of innovative activity of SMEs. SMEs create innovative products directly in the digital economy. Turning to the Bukht-Heeks scheme, it is easy to find that there are significant opportunities for growth in this direction. Theoretically, even one task, the full deployment of Industry 4.0 , is able to load the entire SME sector for many years.

The experience of state support for SMEs in the USA (Atlantic innovative model) is of practical interest when considering the role of state support as a condition for the intensive development of interaction between the $\mathrm{CE}$ and SMEs [18], [19]. The model represents a support system for the entire innovation cycle from the generation of an idea to its commercial implementation. This provides long-term competitive advantages, in contrast to "piecewise" models of support for certain stages.

A successful form of state support for innovative SMEs in the USA is the popular global programs that have proven their effectiveness: SBIR (Small Business Innovation Research) and STTR (Small Business Technology Transfer). Financing for SMEs under the SBIR program is allocated at the first stages of the life cycle of innovative technology and product (in the "death valley"), which are critical. This allows the technology to reach the stage of successful commercialization
(SBIR/ STTR). The key link in the STTR program is the creation of joint ventures of SMEs, non-profit research institutes, and universities. It helps to separate fundamental science from commercializing of its achievements [31].

The law on intellectual property for products was developed under the above programs. Tax credits and the elimination of administrative barriers in the implementation of joint state and industrial $R \& D$ programs also had a positive effect.

All measures work not only to support the innovation process but also help to obtain a high-quality intellectual product from grantees. A grant means recognition of the value and prospects of ideas, which automatically promotes the brand in the innovation market.

- The SME Corporation.

- The central institute for the development of small and medium-sized enterprises.

- The Joint-Stock Company Russian Bank for the Support of Small and Medium Enterprises (JSC SME Bank).

These organizations provide significant support to entrepreneurial activity, provide financial, marketing, property assistance, provide access to public procurement and procurement of large manufacturing corporations. The share of organizations that are engaged in marketing innovation does not exceed $1.5 \%$ in Russia [32]. SME Corporation seeks to increase the participation of SMEs in innovation. The dynamics of the involvement of small and medium-sized businesses in the high-tech sector or the share of high-tech SME products in total deliveries to the largest customers of the Russian Federation is 7.5 in 2016, 10.98 in 2017, 12 in 2018, 12.4 in 2019, 13.4 in 2020 [33].

The total amount under contracts for the supply of hightech products amounted to 29 billion rubles in 2020 . The data show a positive trend, but at the same time, only $10 \%$ of entrepreneurs consider their products innovative in Russia [34]. Nevertheless, the functioning of such state institutions as the Fund for the Promotion of Innovations, Rosmolodezh, and the Regional Platform for Supporting Entrepreneurial Initiatives is gradually changing the situation for the better.

The problems in the speed of digitalization rate in $\mathrm{RF}$ are connected with:

- low using level of information technologies in business (including the sector of small and medium-sized innovative entrepreneurship);

- the lack of appropriate that is needed for introducing digitalization and to entry to the world market;

- the fear of the enterprises' and cooperations' chiefs, including in the small and medium-sized business sector, to introduce the possibilities of $\mathrm{DE}$ for increasing its competitiveness [12].

So, several steps can be introduced to raise the level of digitalization in economics. And first of all, it has to be the 
government support in preparing qualitative specialists and introducing digitalization and computerization in economics sectors (including common using); creating a digital economy system, especially in the field of small and medium-sized innovation entrepreneurship; incoming and raising of the international cooperation, especially in innovative and science cooperation [12] [35].

\section{CONCLUSION}

In accordance with the task, the concepts of the "digital economy" and "innovative development of small and medium-sized businesses" were studied and refined in the research process. An analysis of scientific sources and documents of international organizations confirmed the absence of a single universally accepted definition of a digital economy. In this regard, after analyzing various interpretations, the definition of R. Bukht and R. Heeks was adopted as the most accurate and comprehensive. Further application of this definition and the study of the state of the digital economy of Russia made it possible to establish the level of its development in accordance with the interpretation of the Bukht\&Heeks. The digital economy of the Russian Federation is at the second, intermediate stage of development according to the results. The main barriers to moving to the third level, characteristic of developed countries, are a slight advance towards Industry 4.0 and the practical lack of precision agricultural technology.

The concept of "innovative development of small and medium-sized businesses" was also investigated. As a result, two components were distinguished:

1) Application of innovations, innovative technologies in the business processes of SMEs.

2) SME participation in the innovative development of the economy.

Studying the degree of participation of SMEs in global and national innovation processes, comparing the scale of the digital economy and SMEs, leads to the conclusion that there are two directions in the influence of the digital economy on the innovative development of small and medium businesses. In one of them, the digital economy provides SMEs with the modern tools necessary for the development and implementation of innovative products and also provides SMEs with the tools necessary for business processes in SMEs themselves.

In the next role, $\mathrm{DE}$ is the object of innovative development of SMEs, since within this sector, the demand for innovations is constantly generated. Given the cross-border nature of $\mathrm{DE}$, it is a vast and attractive market for Russian SMEs with significant potential in this area. For its implementation, as the study of the US experience shows, a rational system of state support is needed. To this end, the necessary institutional and legal mechanisms have already been created in the Russian Federation, and funding is growing. However, at the same time, volumes of industrial financing remain low, which is one of the main problems of the digital economy and the innovative development of SMEs.

\section{REFERENCES}

[1] H. Bouwman, S. Nikou, and de M. Reuver, "Digitalization, business models, and SMEs: How do business model innovation practices improve performance of digitalizing SMEs?" Telecommunications Policy, vol. 43, no. 9, pp. 101828, 2019. DOI: 10.1016/j.telpol.2019.101828.

[2] B. Panshin, "Digital economy: concepts and directions of development," The Science and Innovations, vol. 3, no. 193, pp. 49-55, 2019.

[3] N. V. Smorodinskaya, "Complication of the organization of economic systems in the conditions of nonlinear development," The Bulletin of the Institute of Economics of the Russian Academy of Sciences, vol. 5, 2017. http://spkurdyumov.ru/uploads/2018/06/uslozhnenie-organizaciiekonomicheskix-sistem-v-usloviyax-nelineĭnogo-razvitiya.pdf.

[4] V. Efimushkin, "Infocommunication technological space of the digital economy," Digital transformation of business based on the next generation communicative technologies: the round table. March 28 2017, NIU VSHE, 2017. https://bi.hse.ru/data/2017/03/30/1168539176 /КС28.03\%20-\%20Владимир\%20Ефимушкин.pdf.

[5] A. Urmantseva, Digital economy: How professionals understand this term. RIA Nauka, 2017. https://ria.ru/20170616/1496663946.html.

[6] R. Bukht, and R. Heeks, "Defining, conceptualising and measuring the digital economy," International Organisations Research Journal, vol. 13, no. 2, 143-172, 2018.

[7] A. S. Mikhaylov, A. A. Mikhaylova, O.V. Savchina, "Innovation security of cross-border innovative milieu," Entrepreneurship and Sustainability Issues, vol. 6, no. 2, pp. 754-766, 2018. "http://doi.org/10.9770/jesi.2018.6.2(19).

[8] E. M. Akhmetshin, I. Morozov A. V. Pavlyuk, A. Yumashev, N. Yumasheva, and S. Gubarkov, "Motivation of personnel in an innovative business climate," European Research Studies Journal, vol. 21, no. 1, pp. 352-361, 2018.https://www.um.edu.mt/library/oar// handle/123456789/30284.

[9] T. Tolstykh, L. Gamidullaeva, and E. Shkarupeta, "Foreign and domestic initiatives for the development of industrial complexes in the conditions of the fourth industrial revolution," Fortus: economic \& political researches, vol. 1, no. 1, pp. 1-9, 2018.

[10] A. Syritskiy, K. Potapov, A. Komshin, and M. Kiselev, "The fourth industrial revolution: Digital manufacturing and the industrial Internet of things," Standards and Quality, vol. 6, pp. 64-68, 2018.

[11] N. A. Yastreb, “The Fourth Industrial Revolution: Global Industrial Networks and the Internet of Things," Innovacionnyj vestnik "Region" (The "Region" Innovation Bulletin), vol. 4, pp. 22-26, 2014.

[12] V. I.Talantsev, A. K. Ravnyanskiy, "The digital economy and its role in the development of small and medium-sized innovative entrepreneurship in Russia," Regional problems of economic transformation, vol. 2, no. 88, pp. 80-86, 2018.

[13] K. B. Kostin, "Tthe role of digital technologies in the promotion of goods and services in global markets," Russian business, vol. 18, no. 17, pp. 2451-2460, 2017.

[14] I. P. Boiko, M. A. Evnevich, A. V. Kolyshkin, "Economics of the enterprise in the digital age," Journal of Russian entrepreneurship, vol. 18, no. 7, pp. 1127-1136, 2017.

[15] R. Štefko, R. Bačík, R. Fedorko, M. Oleárová, and M. Rigelský, "Analysis of consumer preferences related to the use of digital devices in the e-commerce dimension," Entrepreneurship and Sustainability Issues, vol. 7, no. 1, pp. 25-33, 2019. http://doi.org/10.9770/jesi. 2019.7.1(2).

[16] Huawai Technologies Co.,Ltd., “Global Connectivity Index. GCI Ranking Table,” 2021. https://www.huawei.com/minisite/gci/en/ country-rankings.html.

[17] A. I. Vlasov, V. A. Shakhnov, S. S. Filin, and A. I. Krivoshein, "Sustainable energy systems in the digital economy: Concept of smart machines," Entrepreneurship and Sustainability Issues, vol. 6, no. 4, pp. 1975-1986, 2019. http://doi.org/10.9770/jesi.2019.6.4(30).

[18] V. I. Medennikov, "The impact of the digital economy on the export potential of small and medium enterprises in agriculture," Journal of Chemical Information and Modeling, vol. 53, no. 9, pp. 1689-1699, 2013. 
[19] V. Zimmermann, KfW SME Innovation Report 2018, 2018. https://www.kfw.de/PDF/Download-Center/Konzernthemen/Research/ PDF-Dokumente-Innovationsbericht/KfW-Innovationsbericht-EN/KfWSME-Innovation-Report-2018_EN.pdf.

[20] Ya. Ivanov, "Foreign experience of innovative development of small business," Young Scientist, vol. 12, pp. 306-308, 2013.

[21] A.V. Balyshev, and E. S. Zinovyeva, "Promotion of science and innovation in the U.S.: Support for small enterpises in the small business innovation research (SBIR) program," Vestnik Chuvashskogo Universiteta (Bulletin of the Chuvash University). Humanities, vol. 4, pp. 292-301, 2013.

[22] O. Shulaeva, "The role of development institutions in the support of small and medium-sized enterprises' innovative activities in Russia," Theory and Practice of Social Development, vol. 11, pp. 54-57, 2017.

[23] M. Botnik, G. Sechenya, and N. Mikheeva, "System for assessing and monitoring the innovative development of Russian regions," Innovacionnaya ekonomika (Innovative Economy), vol. 9, pp. 40-61, 2012.

[24] Kirov Regional Fund for Entrepreneurship Support, Foreign experience in state support of innovative small and medium enterprises. (n.d.). http://www.kfpp.ru/analytics/ material/innovation.php.

[25] K. S. Choi, and J. Choi, "Small and medium business and investment decision," Indian Journal of Science and Technology. Indian Society for Education and Environment, vol. 8, no. 24, pp. 1-6, 2015.

[26] UNCTAD. Digital economy report 2019: Overview, 2019. https://unctad.org/en/pages/PublicationWebflyer.aspx?publicationid=25 12.

[27] A. Christopher, The foundation for economies worldwide is small business, 2018. https://www.ifac.org/knowledge-gateway/contributingglobal-economy/discussion/foundation-economies-worldwide-small.
[28] K. Kh. Zoidov, S.V. Ponomareva, E. Simonova, and A. A. Yurieva, "Prospects for the development of the digital economy in Russia," Regional problems of transforming the economy, vol. 12, pp. 18-24, 2018.

[29] Huawai Technologies Co.,Ltd., "Global Connectivity Index. GCI Ranking Table,” 2019. https://www.huawei.com/minisite/gci/en/ country-rankings.html.

[30] R. Ireland, M. Hitt, "Achieving and maintaining strategic competitiveness in the XXIst century: The role of strategic leadership," Academy of Management Executive, vol. 13, no.1, 1999. https://doi.org/10.5465/ame.1999.1567311.

[31] SBIR/ STTR. (n.d.). www.sbir.gov.

[32] T. V. Pogodina, V. G. Aleksakhina, V. A. Burenin, T. N. Polianova, and L. A. Yunusov, "Towards the innovation-focused industry development in a climate of digitalization: The case of Russia," Entrepreneurship and Sustainability Issues, vol. 6, no. 4, pp. 1897-1906, 2019. http://doi.org/10.9770/jesi.2019.6.4(25).

[33] SME Corporation. Providing support to small and medium-sized enterprises by the SME Corporation in the period 2015-2019, 2020 https://corpmsp.ru/upload/001/\%D0\%9F\%D1\%80\%D0\%B5\%D0\%B7\% D0\%B5\%D0\%BD\%D1\%82\%D0\%B0\%D1\%86\%D0\%B8\%D1\%8F\%20 $10.02 \% 202020 \%$ D0\%B3.pdf.

[34] Global Enterprise Monitoring (GEM) (n.d.). http://smb.gov.ru/analytics/17925.html.

[35] J. R. Saura, "Using data sciences in digital marketing: Framework, methods, and performance metrics," Journal of Innovation \& Knowledge, vol. 6, no. 2, pp. 92-102, 2021. https://doi.org/10.1016/j.jik.2020.08.001. 